\title{
Selective Desintegration and Concentration: Theory and Practice
}

\author{
Tatyana Aleksandrova $^{1 *}$, N. Nikolaeva ${ }^{1}$, Holger Lieberwirth ${ }^{2}$ and Alexander Aleksandrov ${ }^{3}$ \\ ${ }^{1}$ Federal State-Funded Educational Institution of Higher Professional Education "Saint Petersburg \\ Mining University", Saint Petersburg, Russia \\ ${ }^{2}$ University of Technology "Freiberg Mining Academy", Freiberg, Germany \\ ${ }^{3}$ Mining Institute of Far eastern branch of Russian Academy of Sciences, Khabarovsk, Russia
}

\begin{abstract}
Investigations on the possibility of selective grinding and benefication of quartz-pecoraite ores of the Ufaleiskoye deposit have been carried out. Methods of computer X-ray microtomography have been used to study the morphometric features and pore volume parameters of samples, and these data was compared with results of quantitative microstructural analysis. The performed research shows the powerful capabilities of X-ray computer microtomography method for solving scientific and practical problems related to the study of physical and mechanical properties of rocks, the determination of ore minerals liberation, the evaluation of their content, the analysis of the granulometric composition and the spatial distribution of their grains. Analysis of mineralogical and geochemical composition of ores showed that these ores meet the criteria for selective disintegration. An analysis of flotation experiments results showed that when material is grinded in a roll mill, the consumption of reagents is $25 \%$ lower than when grinding in a ball mill if the same degree of nickel extraction is achieved. Key words: selective disintegration, flotation, nickel, separation, microtomography.
\end{abstract}

\section{Introduction}

When developing new deposits and designing concentrating factories, they often face problems of processing complex and fine-grained mineral raw materials, which leads to additional costs and an extension of the crushing and grinding scheme for sufficient intergrowth liberation. This trend can lead to an increase in electricity consumption four or more times by 2030 compared to today [1-2]. Thus, a reduction in specific energy consumption in the processes of disintegration and mineral benefication is an obvious task, taking into account the tendency of saving natural resources, as well as reducing the impact on the environment during the processing of mineral raw materials.

One of the ways to solve this problem is the use of selective disintegration [3], which would allow not only to break the rock mass to the required size, but also to carry out pre concentration at the stage of classification to obtain a preliminary concentrate and put the waste rock into the tailings.

*Corresponding author: alexandrovat10@gmail.com 


\section{Theoretical approaches to selective disintegration}

Selective grinding leads to optimal formation and propagation of cracks in one or at once in several components and, consequently, causes differences in the distribution of the valuable component over the size fractions (Table 1).

Table 1. Graphical examples of selective and standard disintegration

\begin{tabular}{|c|c|c|c|}
\hline \multirow{2}{*}{$\begin{array}{c}\text { Raw } \\
\text { material }\end{array}$} & Selective crushing & Selective grinding \\
\hline \multirow{2}{*}{$\begin{array}{c}\text { Initial } \\
\text { material }\end{array}$} & $\begin{array}{c}\text { Standard } \\
\text { disintegration }\end{array}$ \\
product & Crushed &
\end{tabular}

The material's ability for selective disintegration is determined by differences in the physical, chemical, structural, and other properties of the material. Systematization of theoretical data on selective disintegration allowed revealing the system character of selective grinding (Fig. 1) [4-6].

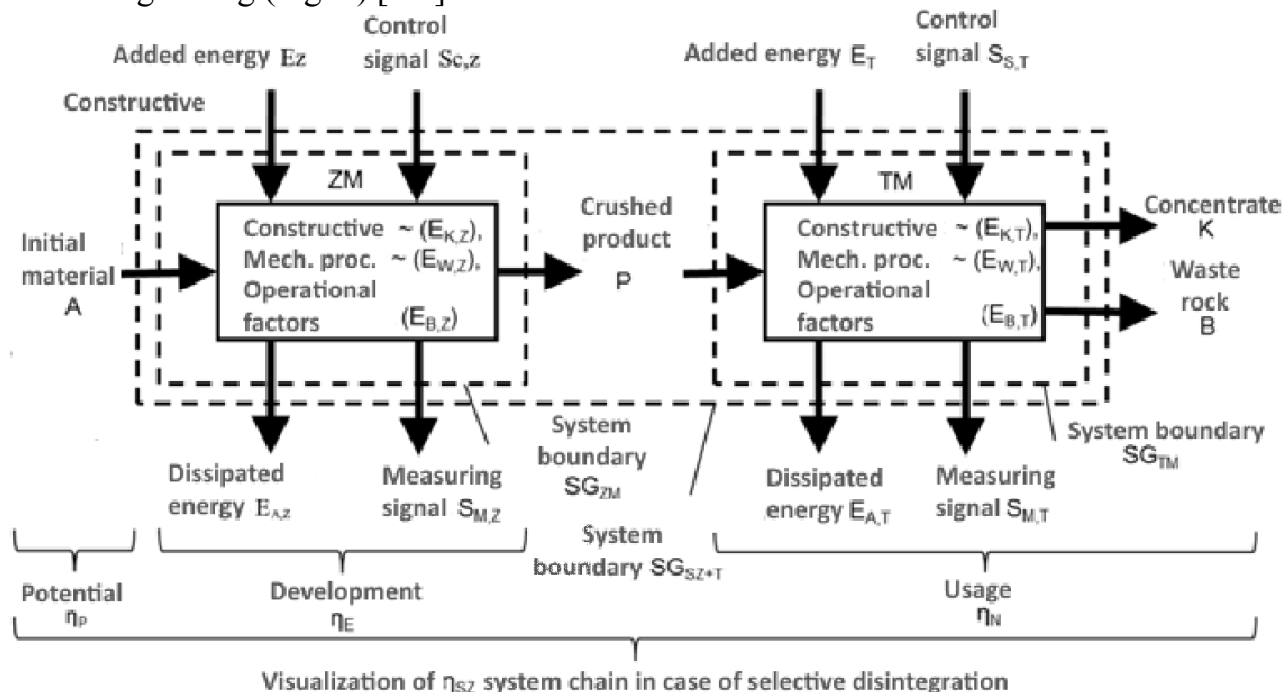

Fig. 1. Black box model for system chain in case of selective disintegration

But in order to qualitatively assess the possibility of selective destruction, it is necessary to quantitatively determine the structural and texture parameters of the ore. For this aim, the quantitative microstructure analysis method (QMA), developed at the Institute of Mineral Processing Machines of Freiberg Mining Academy TU [7-8], is successfully used.

For the implementation of selective disintegration effect, an in-depth study of the mineral components properties of the ore is necessary. Usually, geologists give a description of the texture and structure of ore formations by analyzing microsection or polished sections. This method has limitations, since it is two-dimensional and can only 
give a qualitative description. Obtaining more detailed information on mineral raw materials will allow to reveal the dependencies between the corresponding parameters of breaking, the characteristics of the product and their inherent mineralogical-technological and structural-texture features, which is also an urgent task in the study of selective disintegration processes and the development of devices for their implementation.

Although selective disintegration is sometimes used in concentrating plants [9-10], systematic studies of the processes of selective disintegration are still lacking, as well as systematic data on the influence and interrelation of mineral-technological, structuraltexture and physical-technical properties of minerals, rocks and ores with the processes of selective disintegration and flotation.

\section{Results and discussion}

Quartz-pecoraite ores of the Ufaleiskoye deposit were investigated as an object of research. The deposit has been well studied by Russian geologists [11-12]. Three zones of weathering are distinguished in the field profile: the oxide-iron zone (goethite ores), the nontronite zone (chamosite ores and the zone of leached serpentinites (chrysotile-lizardite and nepouit-chrysotile-lizardite ores). Major part of nickel is contained in the nontronite (chamosite) zone. In some places, this zone can reach a thickness of about $50 \mathrm{~m}$. Ores are a moist clay-like mass with fragments of leached serpentinites, which requires a rather complex process for their benefication. Despite the fact that the main ore zone of the deposit is the zone of nontronite (chamosite) clays, the underlying leached serpentinites also contain nickel concentrations that are profitable for extraction.

A number of typical samples were analyzed by computer tomography.

Sample 1. The distribution of ore minerals in the entire rock volume is shown in Fig. 2, from which it can be seen that it is possible to distinguish on a tomogram dense ore minerals from the silicate minerals of the matrix as effectively as possible, while the latter minerals are quite difficult to distinguish from each other, due to their close X-ray density.
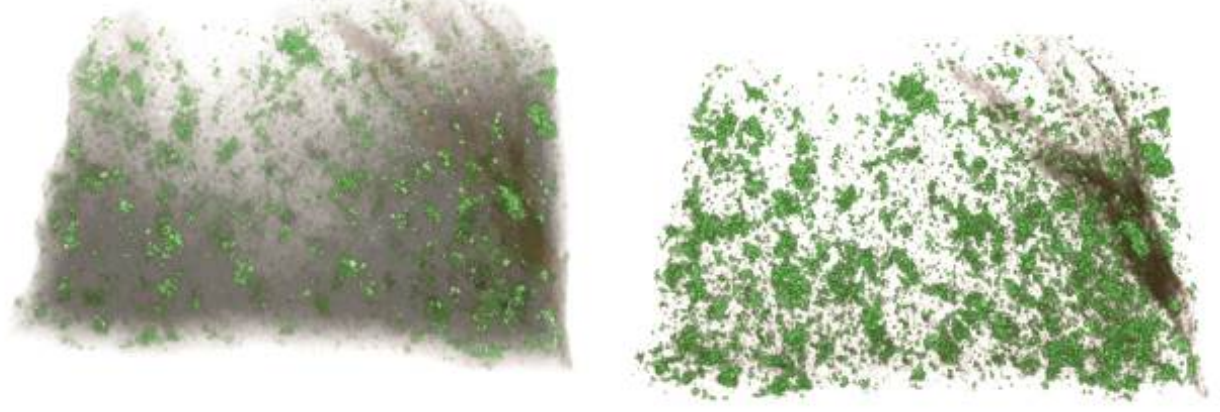

Fig.2. Distribution of ore minerals (green) in a silicate matrix (gray)

Using the CTvox and CTan software (Bruker, Belgium), it is possible to examine in detail and analyze not only the size of the grains composing the rock, but also their mutual relations with each other, which is especially important for technological mineralogy. Ore minerals are rather evenly distributed throughout the rock volume, sometimes forming individual grains with an average grain size of 0.07 and fine aggregates $0.26 \mathrm{~mm}$ in size (Fig. 3A, B), sometimes up to 2.0-4.5 mm (Fig. .3, C). 
A

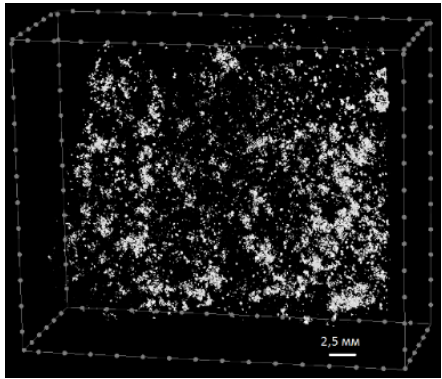

B

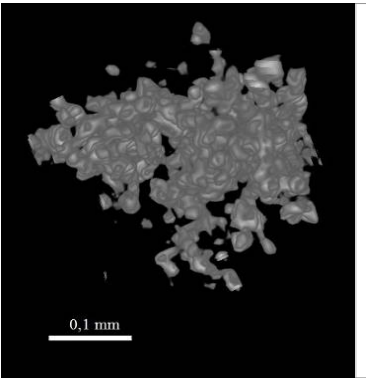

$\mathrm{C}$

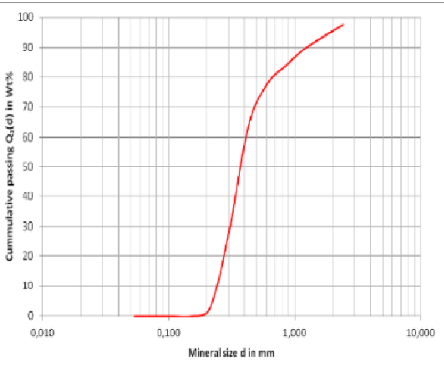

B) and their distribution Fig. 3. Aggregates of ore minerals in the rock
according to the maximum diameter, $\mathrm{mm}(\mathrm{C})$

Ore minerals have a quite isometric shape, sphericity coefficient calculated as the ratio of the short to the long axis (Bruker, Belgium) is 0.78 (this coefficient reaches 1, when the shape of the grain is almost isometric, Fig. 4A). The specific surface of ore minerals, calculated as the ratio of the total surface area of minerals to their volume and representing the degree of sinuosity of the boundaries, is $31.86 \mathrm{~mm}^{2} / \mathrm{mm}^{3}$. The orientation of ore grains and aggregates is marked, expressed quantitatively as the deviation of the longest axis of grains from the vertical in degrees, (Fig. 4 B).

A

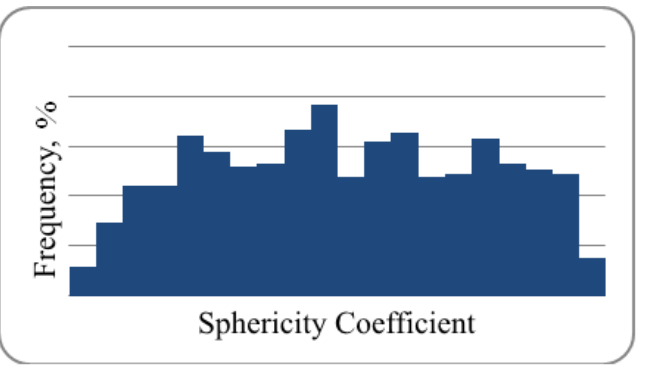

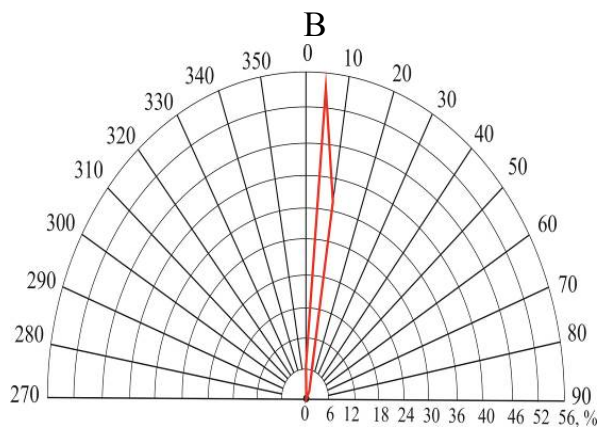

Fig. 4. The distribution of ore minerals aggregates according to sphericity coefficient (A) and orientation of longest axis (B)

One of the most important characteristics for rocks disintegration, linking the strength of the rock with the defectiveness of its structure, is porosity. It is determinant when interpretation of the strength properties and behavior of the rock during disintegration [1315]. The total porosity of the cupriferous sandstone sample is $1.4 \%$, the opened porosity is $0.68 \%$, and the pore connectivity is low. In general, subcapillary pores size is less than $0.0002 \mathrm{~mm}$, the predominant pore size is $25-50 \mu \mathrm{m}$, there are single pores larger than 0.1 $\mathrm{mm}$ in diameter. The pore sphericity factor is 0.62 . The pore density, calculated as the ratio of the number of pores per unit volume of rock, is $9.10 \mathrm{~mm}^{-1}$.

Similarly, samples No. 2 and 3 were analyzed. Comparative analysis of samples porous volume based on CT results revealed that despite the highest total porosity (3.05\%), sample 3 has a minimum pore density $\left(2.03 \mathrm{~mm}^{-3}\right)$, that due to the small pore sizes (15-40 microns) and their isometric shape (Ksf 0.80) leads to increase of rock the strength of the rock. Sample 1 has intermediate parameters of pore volume and medium strength, and sample No. 2 has a minimum strength at minimum parameters of total porosity and maximum values of pore density. By results of researches it is possible to speak that strength of the rocks decreases with reduction of total and closed porosity parameters, as well as pore sphericity coefficient. Rock strength also decreases with increasing of closed pores total quantity and its density. 
Thus, the porosity parameters obtained by the CT method correlate with rocks strength differences, specifically with the strength index Is $(50)[16,17]$, whereas the total porosity, determined from the values of the mineral and bulk densities, allows to indirectly estimate the rock strength and does not provide information on the size, shape of the pores, their connectivity and spatial orientation. In addition, the undoubted advantage of the X-ray tomography method is the possibility of 2D and 3D data visualization with the help of specialized CTvox and CTan software that help analyze not only the size of grains and their aggregates, but also their distribution in the total rock volume and mutual relations with each other .

Since during benefication of serpentinites it is necessary to take into account that the nickel content in the rock may be too low, selective grinding may be required to create a high-quality concentrate in a certain fraction (Figure 5).

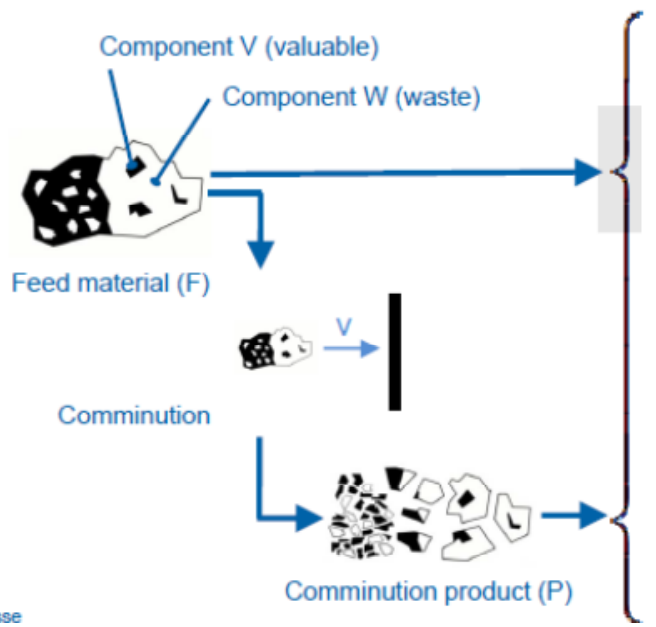

Fig. 5. Selective ore grinding (schematically) (TUBAF, IAM)

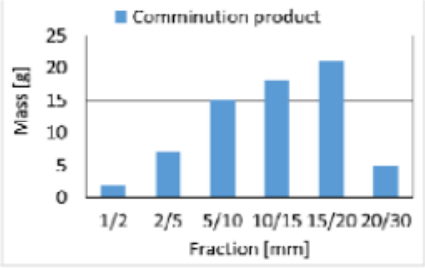

Particle size distribution

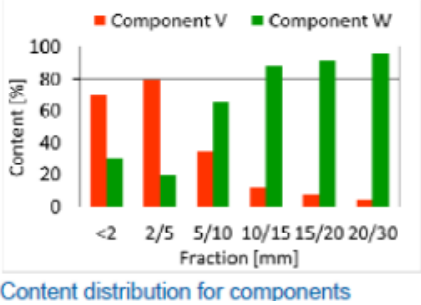

In this case, high-grade nickel ores can be separated from the bulk of serpentinites.

If the nickel content in serpentinites is quite high, then to extract it from the grinded product by subsequent flotation, it is possible to propose a roller mill method (Fig. 6).
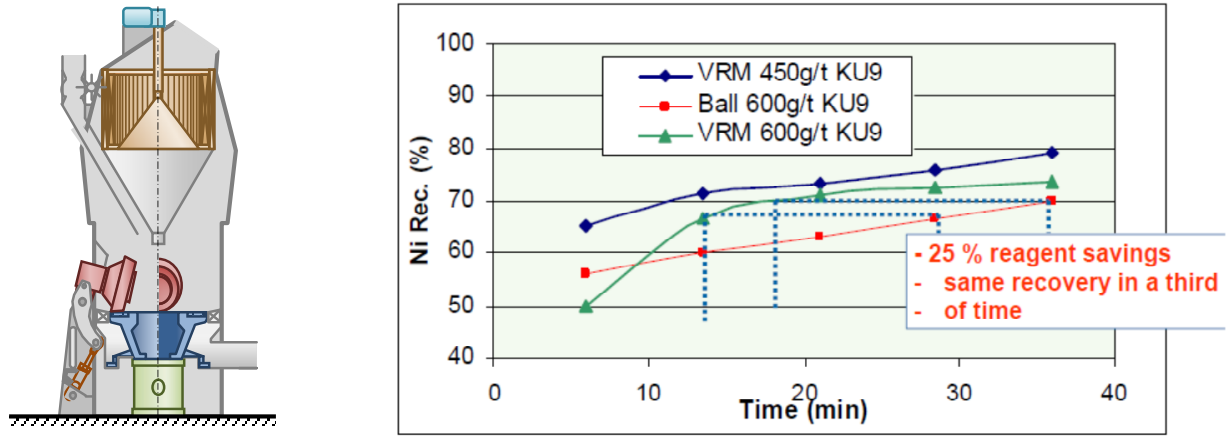

Fig. 6. Results of nickel flotation extraction when grinding in a roller mill (Loesche) and a ball mill

An analysis of flotation experiments results showed that when grinding material in a roll mill, the consumption of reagents is $25 \%$ lower than when grinding in a ball mill when the same degree of nickel extraction is achieved. 


\section{Conclusion}

Morphological characteristics of serpentinites were studied using computer microtomography to study their behavior during disintegration. Rocks containing ore in the hypergene deposits of weathering rinds of the Urals are characterized by a different set of properties that must be taken into account when disintegrating and benefication them.

To increase the efficiency of metal extraction, it is necessary to apply selectivity to valuable and gangue minerals, depending on technical characteristics. Wet and sticky laterites should be separated from solid serpentinites at the stage of ore preparation and preconcentration, which will allow separately processing both types of ores, as well as it is possible to isolate the third grade (loose) for increasing the efficiency of nickel extraction.

\section{Acknowledgment}

The work is carried out with financial support of Ministry of Education and Science of Russian Federation according to grant program "Research and development in priority areas of development of Russia's scientific and technical complex for $2014-2020$ "

\section{References}

1. Norgate, T., Haque, N. Energy and greenhouse gas impacts of mining and mineral processing operations. Journal of Cleaner Production, 18, pp. 266-274. (2010)

2. Norgate, T., Jahanshahi, S. Reducing the greenhouse gas footprint of primary metal production: Where should the focus be? Minerals Engineering, 24, pp. 1563-1570. (2011)

3. Pevnivtsev, et al.: Selektivnoye razrusheniye mineralov. Moskva: Nedra, (1988)

4. Hesse, M.: Selektive Zerkleinerung von Erzen und Industriemineralen bei Prallbeanspruchung. Dissertation, Technische Universität Bergakademie Freiberg, 2017.

5. Hesse, M.; Lieberwirth, H.: Selective comminution for pre-concentration in mineral processing of lead-zinc-ores. ISBN 978-3-940276-64-3.

6. Hesse, M.; Lieberwirth, H.: Selective comminution to increase efficiency in the beneficiation of mineral recourses. ISBN 978-5-94211-724-5.

7. Ohser, J., et al.: Quantitative Gefügeanalyse Theoretische Grundlagen und Anwendung. Freiberger Forschungshefte. doi: 10.1002/maco.19950460411.

8. Popov, O.: Beitrag zur mathematisch-petrographischen Gefügecharakterisierung für die Beurteilung der Festgesteine hinsichtlich ihrer Aufbereitung und ihrer

Produkteigenschaften. Dissertation. Technischen Universität Bergakademie Freiberg, (2007).

9. Puffe, E., 1955. Erfahrungen bei der Prallzerkleinerung in Bergbau-, Aufbereitungs- und Hüttenbetrieben. ERZMETALL, VIII, pp. 570-580.

10. Taggart, F., 1956. Handbook of mineral dressing - ores and minerals. John Wiley \& Sons, Inc

11. Talovina I.V. Geochemistry of the Ural oxide-silicate nickel deposits. / St. Petersburg Mining University. 270 p. (2012)

12. Gayfutdinova (Duryagina) A.M. Osobennosti geologicheskogo stroyeniya platinonosnykh kor vyvetrivaniya Svetloborskogo i Nizhnetagil'skogo massivov, Sredniy Ural. // Problemy osvoyeniya nedr v XXI veke glazami molodykh: materialy mezhdunarodnoy molodezhnoy nauchnoy shkoly. 2. P. 37-39. (2012)

13. Vaysberg L.A., Kameneva Ye.Ye. Izmeneniye struktury gornykh porod pri tsiklichnom zamorazhivanii i ottaivanii // Obogashcheniye rud. 2. p. 28-31. (2015) 
14. Talovina, I.V., Aleksandrova, T.N., Popov, O., Lieberwirth, H. Comparative analysis of rocks structural-textural characteristics studies by computer X-ray microtomography and quantitative microstructural analysis methods. Obogashchenie Rud. 3, P. 56-62. (2017) DOI: 10.17580/or.2017.03.09

15. Talovina, I.V., Lieberwirth, H., Alexandrova, T.N., Heide, G. Supergene oxide-silicate nickel deposits: Mineral-geochemical composition and peculiarities of processing. Eurasian Mining. 2017 (1). P. 21-24. (2017) DOI: 10.17580/em.2017.01.06.

16. ISRM - International Society for Rock Mechanics (1985): Suggested method for determining point load strength. Commission on Testing Method. Working Group on Revision of the Point Load Test Method. Int. J. Rock Mech. // Min. Sci. \& Geomech. Abstr.. 22 (2). P. 51-60. (1985)

17. Raaz, V. Charakterisierung der Gesteinsfestigkeit mit Hilfe eines modifizierten Punktlastversuches. In: Z. Geol. Wiss. 30. 3. S. 213-226. (2002) 